\title{
EL SILENCIO JUDICIAL \\ ANÁLISIS FENOMENOLÓGICO Y NORMATIVO DEL PRELUDIO A LA DECISIÓN JUDICIAL
}

\author{
"Oh, Dios, no guardes silencio, \\ no calles, oh Dios" \\ Salmo 83:1
}

"No hables si lo que vas a decir no es más hermoso que el silencio."

Proverbio árabe

\section{JOSUÉ PARIONA PASTRANA*}

\section{Resumen}

El presente aporte es una aproximación cercana a lo que debería ser la actuación del Magistrado respecto a cómo interpretar el silencio judicial y cómo ha de actuar cuando se encuentre en él.

Palabras clave: Silencio judicial - Decisión judicial.

\begin{abstract}
This brief is a close approximation of how a Judge must interpret the judicial silence and how he must act in the event of its existence.
\end{abstract}

Key words: Judicial Silence - Judicial Decision.

El tema sobre el cual hoy disertaré no pertenece al ámbito de lo que se denomina "jurídico" en sentido estricto, pues no abarcaré un tema de dogmática procesal o sustantiva, ni de política criminal. Hoy vengo a dar una propuesta sobre un aspecto que vendría a ser catalogado por muchos como banal o fútil de cara a la resolución de un problema jurídico. No obstante, dar una opinión tan categórica y con una carga semántica negativa concluyente no es muchas veces justo, y menos preciso.

\footnotetext{
* Juez Supremo Titular de la Corte Suprema de Justicia de la República - Poder Judicial del Perú.
} 
Tanto la historia del sistema penal, como la historia de toda ciencia -sea social o exacta- en general nos han demostrado que muchos temas que se tienen como verdades obvias o aparentemente intrascendentes, tienen en la realidad un valor mucho más alto del que sus críticos consideraban. En el ámbito jurídico penal son abundantes los ejemplos en la dogmática que comprueban esta afirmación. Tal es el caso de la ubicación del dolo en la estructura de la teoría del delito, el cual se consideraba por muchos años perteneciente a la culpabilidad. En el mismo sentido, otro claro ejemplo es la aceptación -como verdad incuestionable- de que el Magistrado ejerciera simultáneamente las labores de Instructor y de Juzgador, hecho que sólo recientemente -desde la visión del constitucionalismo- comenzó a ser cuestionado.

Todos estos ejemplos nos llevan a la misma conclusión: El conocimiento, fundamentalmente en las ciencias sociales, varía constantemente. No existen verdades universales, sino que las mismas dependen en realidad de la época en la que surgen.

Sin más preámbulos pasamos a disertar el tema que nos convoca hoy: el silencio judicial. Adelantamos, que nuestro análisis no se avoca a la resolución del problema derivado de la falta de un pronunciamiento judicial en un plazo determinado -tal como también podría entenderse-, sino que incidirá en el acto reflexivo del Magistrado previo a la emisión de una decisión y posterior a la conclusión del debate oral.

\section{II}

Desde una perspectiva fenomenológica, el silencio puede ser definido como la ausencia de sonido. La perspectiva es correcta, porque efectivamente no puede existir silencio si es que no tiene una contraparte que es el sonido. No obstante, la carga semántica que trae consigo el silencio va más allá de expresar una ausencia, por lo que no puede ser limitada a una definición por oposición. El silencio al interior de un proceso comunicativo no puede ser entendido solamente como una ausencia, sino que por el contrario debe comprendérselo como si fuera una pausa en la comunicación. Un paréntesis entre un primer y segundo momento. Un espacio de necesaria reflexión que precede a una ruptura en la normalidad de la comunicación. En esa misma línea de pensamiento, puede considerarse que el silencio es el enlace necesario entre la situación precedente y la situación posterior.

La definición que proponemos de silencio, como pausa que precede a un cambio entre dos estados, se encuentra presente en diversas situaciones. 
En primer lugar, el silencio también está presente en la teología y es conocido como el Silencio de Dios. Cuando se produce esto, no quiere decir que la humanidad se vio privada de su presencia y de su testimonio, sino que más bien significa que no hay comunicación nueva de parte de Dios para los seres humanos.

Son dos momentos cruciales en la historia sagrada donde se produce aquello. La primera en el Monte Sinaí, en la dación del Decálogo, donde al subir Moisés a dicho monte hay un espacio de tiempo que Dios no se comunica y después de ese lapso escribe en dos tablas de piedra los 10 Mandamientos, que vienen a ser principios cortos y claros, que sirvieron para el avance humanitario del derecho. Por ejemplo, en relación al derecho laboral, estipuló lo que hoy llamamos el derecho al descanso semanal de todo trabajador; y en el área penal, reguló varios tipos penales que subsisten en la actualidad: homicidio, hurto, calumnia e injuria.

El Segundo momento se produce entre el siglo cuarto antes de Cristo y el siglo primero después de Cristo, que abarca un periodo de 400 años, siendo el último profeta del Antiguo Testamento Malaquías.

A este episodio se le conoce como el periodo intertestamentario, pues Dios deja de ofrecer su revelación, su plan, su comunicación con el pueblo elegido -el pueblo judío-, pero la historia, la filosofía, la teología siguió su camino al interior del judaísmo. Fueron años que incluyeron guerras, incertidumbre socio política, con breves momentos de independencia, subyugación y produjo una serie de cambios geopolíticos en la zona del Mediterráneo, donde se ubicaba Judea, al establecerse 3 centros geopolíticos como son Alejandría, Siria y Roma.

En dicho periodo el helenismo intentó amalgamar la filosofía y las creencias paganas con el judaísmo, correlacionando el conocimiento existente sobre el universo en forma sistemática e integrando la experiencia humana con ella, indicando que la formulación de conocimiento en un sistema coherente debía ser gobernada por las reglas que el hombre lógico había ideado. Filón de Alejandría buscó vincular la esencia del judaísmo a los instrumentos de la razón griega, sosteniendo que la fe mosaica y la filosofía griega coincidían en su aspiración a la verdad.

Igualmente, se desarrolló el gnosticismo, un sistema que prometió la salvación por el conocimiento. La materia era el mal, el espíritu era lo verdadero, el cuerpo irreal, y por lo tanto, su satisfacción no tenía ningún efecto en la salvación última del individuo. 
El silencio de Dios se rompe con el nacimiento de Jesús de Nazaret y su historia relatada en el Nuevo Testamento, lo cual a partir de dicha fecha ha tenido y tiene una influencia poderosa en los quehaceres de la humanidad, pero su obra podemos resumir en dos ámbitos, el salvífico, traducido en fe, esperanza y caridad, y al cambio de estructuras imperantes, que ha servido para las grandes reformas que son: no diferencias sociales, de sexo y edad, la equiparación de la mujer y el niño que son baluartes en el momento actual.

En segundo lugar, los ejemplos más cercanos sobre el silencio los podemos encontrar en la naturaleza. La presencia de un maremoto en la costa viene precedida por un retiro del mar de su cauce normal por un breve lapso. La calma que caracteriza los momentos previos a este fenómeno genera externamente una ausencia de sonido; sin embargo, más allá de ese dato sensorial, es más importante el mensaje que esa calma anuncia: la llegada de un suceso natural (el maremoto) que alterará el orden preexistente.

En tercer lugar, el silencio también se encuentra en el arte, específicamente en la música, pudiendo llegar a distinguirse tres tipos de silencio al interior de ella. Uno inicial que es el de expectación previa al inicio del sonido, la función del silencio es que el futuro receptor se prepare para el mensaje a recibir; el intermedio que enlaza dos momentos de la partitura, el cual sirve para entender el sentido comunicativo de la melodía, pues permite al espectador tomar una pausa para asimilar mejor la música; y uno final, que es el necesario para el recuerdo de la melodía. La importancia del silencio para la música es absolutamente indiscutible. El silencio sirve para que la audiencia pueda reflexionar y comprender mejor el mensaje trasmitido a través de la melodía. En cada etapa del silencio musical existe un común denominador: el silencio, es el medio indispensable para entender el sonido. Es el preludio indispensable para que el público disfrute adecuadamente cada una de las etapas de la composición.

El ámbito judicial no se encuentra exento de esta lógica y en él también podemos encontrar un silencio. El silencio judicial siempre ha pasado desapercibido, por lo que no ha sido objeto de mayores estudios. Su análisis no pertenece sólo a un ámbito fenomenológico, sino que también se encuentra presente en los cuerpos normativos nacionales. En la especialidad penal, el caso más claro del silencio judicial regulado, es el previsto en el art. 392, numeral 1 del Código Procesal Penal de 2004: la deliberación producida una vez culminado el debate oral. El juicio oral es un espacio comunicativo donde impera el debate, especialmente la búsqueda de las partes de asignarle un sentido (un sonido) a los argumentos probatorios y jurídicos que sustentan, 
con el objeto de convencer al Magistrado de que su postura es la que él deberá asumir. Posteriormente, culminado el debate el Magistrado ha de deliberar en secreto acerca de los argumentos expuestos por las partes y adoptar una posición sobre ellos, sea para acogerlos o rechazarlos. Finalmente, una vez producida la deliberación es emitida una sentencia en la cual consta el razonamiento del Magistrado y las consecuencias jurídicas emanadas de él.

De los tres momentos listados, la atención se concentra sólo en el primer y el tercer momento, pues ambos son actos públicos y por lo tanto sujetos al escrutinio de la ciudadanía. Ambos actos son comunicaciones, en la medida que son actos intersubjetivos que expresan un significado que va más allá de la subjetividad del emitente. Por ende, como todo acto comunicativo, ambos deben ser considerados como sonidos (entendiendo naturalmente al sonido como una comunicación), pues sólo a través de la alteración del silencio es que ambos podrán lograr su cometido final: que el mensaje sea recibido por el receptor.

A diferencia de ellos, que son actos públicos y comunicativos (lo que implica un debate intersubjetivo), la deliberación es un acto privado e interno. En primer lugar, no se trata de un acto público, por el contrario, en esencia se trata de un acto estrictamente privado, el cual pertenece a la esfera íntima del Magistrado. En segundo lugar, no es un acto comunicativo, porque si bien la deliberación tiene como objeto final la adopción de una decisión que se expresará en la sentencia, la misma sólo es un primer paso en el proceso de comunicación (formación del mensaje).

Si el debate y la sentencia son sonidos, entonces el silencio existente es pausa reflexiva que sirve al Magistrado para adoptar una decisión que será tomada sobre la base de todo lo debatido. Es decir, el silencio produce una reflexión, que va a determinar una decisión sobre la materia que este conociendo el Juez.

\section{III}

El silencio judicial aparentemente se expresa de forma distinta en razón de que la actuación del Magistrado sea -según los términos del nuevo Código Procesal Penal- unipersonal o colegiada.

En el caso del Juez Unipersonal el silencio es mucho más evidente, toda vez que siempre se tiene en mente que el silencio es un acto que proviene 
de una persona exclusivamente y no de un colectivo. De ahí que podría pensarse, erróneamente, que el silencio judicial sólo es posible de ser tenido en cuenta como una actividad ascética, la misma que necesariamente excluiría la actividad plural.

Si entendemos al silencio como un acto reflexivo previo al proceso deliberativo, entonces en realidad esta reflexión precedente no realiza ninguna distinción de singularidad o pluralidad. El silencio yergue como la pausa entre dos estados, el cierre de la comunicación de las partes y la comunicación de la decisión judicial. Pretender realizar una distinción entre ambos y negar la existencia de un silencio colectivo sería el equivalente a negar la posibilidad de que existiera la música en orquesta, puesto que para su producción se requiere de un conjunto de personas y no de una sola. $\mathrm{Y}$ es precisamente la actuación múltiple, coordinada, armónica, usando uno o más tipos de instrumentos, lo que permite a la orquesta reproducir la belleza de una melodía.

Cuando se trata de la actuación judicial unipersonal, el Juez es amo y señor de su propio silencio. Por ello, le es mucho más fácil realizar normalmente sus actividades y realizar la deliberación. No obstante, en el caso de la actuación judicial colectiva es el que presenta un verdadero reto, pues implica una actuación concertada y sincronizada, que permita armonizar los diversos silencios (tres o cinco según la instancia). En este segundo tipo de silencio judicial el Magistrado no se limita a realizar una reflexión personal, sino que produce una reflexión colectiva.

Una característica central del silencio colectivo es la necesidad de que el Magistrado se convierta en un garante de la actividad de sus colegas, a efectos de guardar armonía en la reflexión. Sólo con una actuación coordinada el silencio podrá surtir el efecto reflexivo deseado. De no producirse esta armonía en la actuación del órgano colegiado, entonces la comunicación a producir (la decisión judicial) no estará exenta de sufrir una serie de vicios derivados de su construcción arrítmica.

Si bien se ha puesto énfasis al área penal, aquello no descarta que también se produzca en las otras especialidades como son las áreas constitucional, civil, comercial, laboral, familiar, contencioso - administrativo, y ahora en el novísimo Juez de Tránsito. 
Hasta este punto hemos llegado a definir que es el silencio y cómo se entiende en el ámbito jurídico. No obstante, lejos de realizar un análisis descriptivo, consideramos necesario realizar una propuesta de reglas que ha de tener en cuenta el Magistrado durante el trascendental periodo de silencio, las cuales pueden observarse fenomenológica y normativamente.

\section{Primero: Alejarse Del RUido}

El debate es el proceso comunicativo en el que las partes buscan convencer al Magistrado de su postura. El silencio del Magistrado exige que no exista perturbación externa en su proceso deliberativo. Esta perturbación (alteración del silencio) puede entenderse en dos sentidos. En primer lugar, como la presencia fenomenológica de sonidos que perturben el ambiente donde se produzca la deliberación. Esto es, que el Juez debe dejar de lado los ruidos: noticias periodísticas, opiniones y comentarios sobre el tema. En segundo lugar, como la presencia de actos probatorios y argumentaciones que pretendan influir en el debate, y que no hayan sido materia del mismo.

El Código Procesal Penal de 2004, como es natural, se refiere al segundo punto. La deliberación sólo ha de contener aquello que ha sido materia del debate. Por tanto, no puede incorporarse pruebas que no han sido materia de debate, conforme lo expresa el art. 393 del mencionado cuerpo sustantivo.

\section{SEgundo: ProcuraR NO DEMORAR EXCESIVAMENTE LA DELIBERACIÓN}

La comunicación es un proceso continuo, que si bien no es instantáneo, sino que puede tomar un tiempo en realizarse, este no ha de ser muy prolongado porque se pierde la secuencia entre el acto comunicativo previo y el mensaje posterior.

Un claro ejemplo de ello lo encontramos en el silencio intermedio en la música. La partitura tiene un punto de quiebre que genera expectativa entre el momento previo y el momento posterior. Si el músico demora excesivamente el silencio, entonces pierde la concentración del público y la secuencia musical, lo que deviene en la pérdida de armonía.

En el caso del ámbito judicial el silencio que toma el Magistrado no es considerado eterno, pues conforme pase el tiempo el debate realizado por las partes corre un mayor riesgo de esfumarse de su memoria. Por ello, el 
Código Procesal Penal de 2004 establece en su art. 392, numeral 2, que el periodo de deliberación no puede exceder los dos días, o a lo sumo tres en caso de enfermedad del Magistrado, pudiéndose extender al doble para procesos complejos, y en el caso de la sentencia casatoria es de 20 días, Art.430 inc. 6 del Código Adjetivo. Para los demás casos que no están regulados por el Código Procesal Penal de 2004, se aplica supletoriamente la Ley Orgánica del Poder Judicial, que establece un plazo de 15 días para resolver la causa después de producida la vista, la cual puede ser prorrogada por igual lapso de tiempo.

La consecuencia de prolongar excesivamente el periodo de deliberación es que el mensaje que se pretenda emitir carezca de legitimidad, porque el emisor ha perdido la inmediación con el acto comunicativo previo. Por ello, el art. 392, numeral 3, del Código Procesal Penal establece como consecuencia ante un silencio excesivo la necesidad de repetir el juicio oral, y en otras áreas acarrea una sanción disciplinaria administrativa.

TERCERO: CUIDAR QUE SE MANTENGA LA ARMONÍA ENTRE EL PRIMER Y EL TERCER SONIDO

El silencio es una pausa reflexiva que sirve para dar una respuesta que sea coherente con el sonido previo. Si el ruido del mar cesa y este se retira, entonces se prevé que un maremoto llegue. Si una persona emite una pregunta, espera una respuesta que tenga relación directa con ella.

En ese sentido, la armonía sólo podrá ser alcanzada cuando exista congruencia entre el primer y el tercer sonido. Entre las peticiones que realicen las partes y el fallo al que arribe el Magistrado. Entre las razones expresadas por el Magistrado y el fallo al que arribe. Es labor del Magistrado lograr que la decisión sea congruente, siendo el momento en que guarda silencio, el adecuado para procurar esta armonía. Esta labor no sólo es un consejo, es en realidad un deber de todo Juez, tal y como lo exige el art. 397 del Código Procesal Penal de 2004.

\section{V}

Nuestro aporte en la presente disertación no pretende ser una verdad universal sobre cómo interpretar el silencio judicial, y cómo ha de actuar el Magistrado cuando se encuentre en él. Tan sólo es una aproximación cercana a lo que debería ser su actuación. 